\title{
PESQUISA-AÇÃO COMO ESTRATÉGIA PARA O APRENDIZADO EM COMUNICAÇÃO DE MÁS NOTÍCIAS: PERCEPÇÃO DISCENTE SOBRE O ROLE-PLAY AGREGADO A UM MOBILE LEARNING
}

\author{
Moana Cavalcante ${ }^{1}$, Maria Viviane Vasconcelos ${ }^{2}$, Suely Grosseman ${ }^{3}$, \\ Célia Maria Silva Pedrosa ${ }^{4}$ e Cynthia de Jesus Freire ${ }^{5}$ \\ 1,2,4 e 5 Universidade Federal de Algoas, Brasil, ${ }^{1}$ moanacavalcante@yahoo.com.br \\ ²camposdelisboa@gmail.com, ${ }^{4}$ elpedrosa@gmail.com, ${ }^{5}$ cynthiamola@hotmail.com \\ ${ }^{3}$ Universidade Federal de Santa Catarina, Brasil, sgrosseman@gmail.com
}

\begin{abstract}
Resumo. A comunicação é uma ferramenta imprescindível ao exercício do trabalho médico e à construção da relação médico-paciente, que exige uma boa capacidade, inclusive, para a comunicação de más notícias. Este trabalho objetivou analisar a percepção do interno acerca da obtenção de habilidades comunicativas e relacionais através de uma estratégia educacional, contribuindo para o ensino da habilidade de comunicação de más notícias. Trata-se de uma pesquisa-ação realizada com estudantes de medicina em estágio no internato, utilizando a técnica do role-play agregada a um aplicativo móvel para o treinamento dos internos. O estudo teve como instrumentos de pesquisa um formulário de avaliação e o diário do pesquisador. Para análise dos dados, aplicaram-se a estatística descritiva e a técnica de análise de conteúdo. Os resultados demonstraram que o uso da estratégia foi eficaz para a motivação no treinamento e para o alcance das habilidades necessárias à comunicação de más notícias.
\end{abstract}

Palavras-chave: Comunicação de Más Notícias; Estratégia Educacional; Habilidade de Comunicação; Pesquisa Qualitativa; Educação Médica. ACTION RESEARCH AS A STRATEGY FOR LEARNING BAD NEWS COMMUNICATION:
STUDENT PERCEPTION ABOUT ROLE-PLAY ADDED TO MOBILE LEARNING

\begin{abstract}
Communication is a essential tool for medical work and construction of the doctor-patient relationship, which requires good communication skills, including the communication of bad news. This work proposes a teaching strategy for the acquisition of the "bad news" communication skill through the use of a mobile application integrated with the role-play technique. It is an action research in the educational modality carried out with medical students in internship at the boarding school and used several workshops with the role-play technique added to a specific mobile application for the training of students. Immediate effectiveness was assessed using an assessment form (checklist) of the demonstrated skills, and the content analysis was adopted for the researcher's observation data (field diary). The results showed motivation in training and presence above $70 \%$ for all five skills assessed (preparation, perception, information, emotions, monitoring).
\end{abstract}

Keywords: Communication of Bad News; Educational Strategy, Communication Skills; Qualitative Research; Medical Education.

\section{INTRODUÇÃO}

A comunicação é uma ferramenta imprescindível ao exercício do trabalho médico e à construção da relação médico-paciente, que exige uma boa habilidade, inclusive, para a comunicação de más notícias. O paciente é a fonte de informações necessárias ao médico para a construção da hipótese diagnóstica, e, quando bem atendido, sente-se seguro, adquire confiança, melhora a adesão ao tratamento e aceita mais facilmente as restrições em relação a antigos hábitos (Stiefel et al., 2010). Nesse sentido, a relação médico-paciente entendida 
como atuação fundamental do médico tem como alicerce a comunicação e para tal deve ser estudada na prática médica e ministrada nos cursos de treinamento especialmente na área pediátrica (Turini et al., 2008).

O termo "má notícia" define a informação com significado negativo na vida do paciente e de seus familiares (Nonino, Magalhães, \& Falcão, 2012). O momento da transmissão é tenso: para o informante, uma tarefa desconfortável; para o paciente, um evento doloroso. $\mathrm{Na}$ maioria das vezes, o profissional não foi preparado para essa incumbência. Nesse momento, podem ocorrer extremos: discursos eufemistas, que mascaram a real informação, ou discursos rudes, que agravam a percepção dos fatos (Victorino, Nisenbaum, Gibello, Bastos, \& Andreoli, 2007).

A comunicação de más notícias ( $\mathrm{CMN})$ é uma necessidade percebida desde a criação do primeiro código de ética médica dos Estados Unidos, em 1847 (Girgis \& Sanson-Fisher, 1995). Protocolos foram criados para o ensino das más notícias, como o SPIKES e as Diretrizes Curriculares Nacionais para os cursos de graduação em Medicina (DCN), que dão ênfase às habilidades de comunicação. Apesar disso, o tema ainda não está presente de maneira efetiva na matriz curricular dos cursos de graduação médica. As DCN trazem, como algo esperado do egresso, a aquisição de competências, compreendidas como a capacidade de mobilizar conhecimentos, habilidades e atitudes, como iniciativas capazes de solucionar os desafios da prática profissional (Brasil, 2014). Desenvolver habilidades comunicativas e relacionais é fundamental na formação médica, pois, por meio delas, se estabelecem vínculos afetivos com os pacientes, se compreende melhor sua história e, assim, podem-se propor estratégias de tratamento integradas com os familiares e os membros da equipe (Rabelo \& Garcia, 2015).

Traiber e Lago (2012) citam pesquisas com participantes que descrevem medo, desconforto e ansiedade para comunicar más notícias. Há consenso sobre a necessidade de maior treinamento nesse sentido. Em um estudo com internos da faculdade de medicina de uma universidade federal do nordeste do Brasil, os participantes informaram ter vivenciado a experiência prática sem treinamento prévio. A vivência foi relatada como uma situação difícil e indesejada, sem a devida orientação (Cavalcante, Vasconcelos, \& Grosseman, 2017a).

O estudo de Leal-Seabra e Costa (2015) com médicos recém-formados na Universidade do Porto mostrou serem necessários programas longitudinais de formação nos currículos de medicina, em contextos de treino simulados e reais. Foram desenvolvidas estratégias de educação para médicos e internos, tais como aulas didáticas, discussões em grupos e 
práticas de atendimento clínico. Para Rosenbaum, Ferguson e Lobas, (2004), as estratégias com simulação interpares parecem ser as mais promissoras, por oportunizarem a discussão de problemas e competências e a vivência na perspectiva do paciente, bem como por proverem um feedback. A desvantagem é a necessidade de maior tempo de dedicação dos instrutores. Outra estratégia que emerge como tendência é o uso da tecnologia móvel como parte de um modelo de aprendizado integrado. Consiste no uso de dispositivos móveis na educação, levando à criação de um novo conceito, o chamado mobile learning ou m-learning (Ahonen, 2003, citado por Marçal, Andrade, \& Rios, 2005; Syvänen, 2003, citado por Marçal, Andrade, \& Rios, 2005).

Com base no estudo de Cavalcante, Vasconcelos e Grosseman (2017a), surgiu o seguinte questionamento: como melhorar o ensino-aprendizagem das habilidades comunicativas e relacionais, como a comunicação de más notícias, para o interno de medicina? Nesse sentido, o trabalho objetivou analisar a percepção do interno acerca da aquisição dessas habilidades por meio da tecnologia móvel e de uma técnica de simulação, contribuindo para o desenvolvimento da habilidade de comunicação de más notícias.

\section{PERCURSO METODOLÓGICO}

O estudo foi aprovado pelo Comitê de Ética em Pesquisa da Universidade Federal de Alagoas (Ufal), sob o número CAAE: 45169715.0.0000.5013. Trata-se de uma pesquisa-ação na modalidade educacional (pesquisa-ensino), com abordagem mista concomitante (QUAL+quan).

Os procedimentos adotados no estudo seguiram o fluxograma apresentado na figura 1.

O estudo foi realizado no Hospital Universitário Professor Alberto Antunes (Hupaa) - que pertence à Ufal -, em salas de aula convencionais, durante os meses de julho, agosto e novembro de 2018 e fevereiro e agosto de 2019, sob a condução de um docente e um preceptor (pesquisador), e sob aval do supervisor do estágio em cirurgia geral.

As pesquisadoras são docentes da Faculdade de Medicina e preceptoras de estágio no Hupaa, com vivência nos cenários de ambulatório e enfermaria das clínicas cirúrgica e pediátrica. 


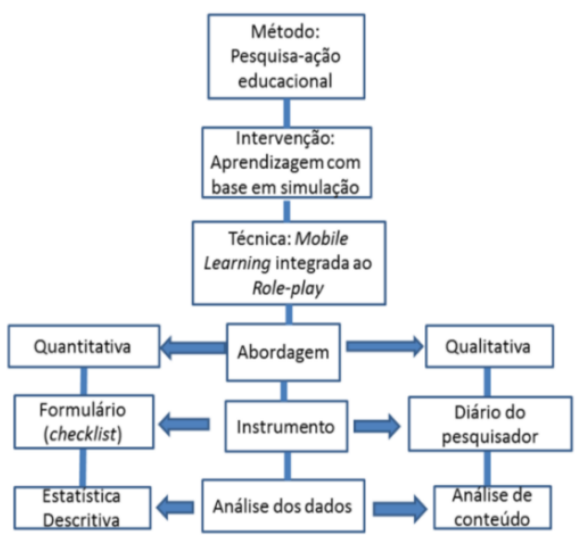

Figura 1. Fluxograma da metodologia utilizada na pesquisa (2019).

Para a constituição da amostra intencional, foram convidados todos os internos do nono período da Faculdade de Medicina da Ufal regularmente matriculados no internato (estágio obrigatório supervisionado) e em rodízio no estágio de cirurgia geral. O curso de medicina da Ufal tem duração de seis anos (12 períodos), com internato nos dois últimos. Para preservação de sua identidade, os internos receberam como código o nome "interno" seguido do número correspondente à sua ordem de participação.

\subsection{Referencial teórico-metodológico}

Trata-se de uma pesquisa-ação educacional (pesquisa ensino) com abordagem de métodos mistos. E que se caracteriza como uma pesquisa dentro da prática pedagógica desenvolvida pelo pesquisador, enquanto preceptor e os estudantes, mas também como uma intervenção na realidade estudada. Essa atuação conjunta dos envolvidos na delimitação do problema, bem como na definição da intervenção a ser executada e na reflexão sobre a ação, aumenta o conhecimento de todos os envolvidos no processo e caracteriza o caráter intervencionista da pesquisa-ação.

Segundo Michel Thiollent (2011), a pesquisa-ação tem como premissa a intervenção no fenômeno, proporcionando um acesso maior à realidade para a elaboração de análises e teorizações. De acordo com Tripp (2005), o ciclo da pesquisa-ação inclui a produção de dados sobre os efeitos de uma mudança na prática, durante a intervenção, antes e depois da sua implementação. Para Malheiros (2011), a pesquisa-ação é muito útil em educação, sendo aplicada para testar novos modelos de ensino, alterações curriculares, formulação de estratégias de aprendizagem, métodos de avaliação, entre outros. 
Concorda-se com Penteado e Garrido (2010), que situam a pesquisa-ensino: a) entre as várias possibilidades de abordagem da pesquisa-ação, que propiciam diferentes aproximações do fenômeno; e b) em relação aos agentes dessa modalidade, aos seus papéis e às contribuições que produzem.

A abordagem com métodos mistos caracteriza a combinação das perspectivas quantitativa e qualitativa, concomitante ou sequencialmente, e envolve concepções filosóficas. A pesquisa demandou uma abordagem mista por tratar de um tema complexo da área da saúde, podendo trazer, assim, maior compreensão do fenômeno (Creswell,2010).

As técnicas de aprendizagem com simulação apoiam-se na Teoria do Aprendizado Experimental (TAE), que traz a aprendizagem como resultado da compreensãotransformação da experiência.

A TAE propõe que o desenvolvimento se dá num ciclo com quatro estágios: experiências concretas (estágio 1) formam a base para observações reflexivas (estágio 2) que, por sua vez, se transformam em conceitos abstratos (estágio 3) e produzem implicações para a "ação" (estágio 4) que podem ser testadas e gerar novas experiências (Kolb \& Kolb, 2005).

\subsection{Protocolo do Estudo}

A pesquisa faz parte de um estudo master realizado, inicialmente, no intuito de avaliar o preparo dos internos de medicina para comunicar más notícias (Cavalcante, Vasconcelos, \& Grosseman, 2017a).

O estudo apontou que o ensino da $\mathrm{CMN}$ não era regular na instituição, o que levou ao desenvolvimento do aplicativo móvel que foi utilizado nesta pesquisa.

De acordo com Malheiros (2011), na modalidade educacional, a pesquisa-ação costuma constituir-se em duas etapas: a diagnóstica, que consiste no entendimento da realidade e do contexto do problema, e a terapêutica, que consiste na efetivação da intervenção.

Nesta pesquisa, adotaram-se as seguintes etapas, com seus respectivos atores e procedimentos metodológicos (Tabela 1): 
Tabela 1. Ciclo da pesquisa-ação educacional desenvolvida como estratégia metodológica de ensinoaprendizagem da habilidade de comunicação de más notícias (2019).

\begin{tabular}{|c|c|c|}
\hline ETAPAS & PARTICIPANTES & PROCEDIMENTOS \\
\hline 1. Diagnóstica & $\begin{array}{l}\text { Internos, } \\
\text { pesquisadora e } \\
\text { docentes. }\end{array}$ & $\begin{array}{l}\text { OSCE (Objective Structured Clinical Examination) = técnica de } \\
\text { simulação para avaliação + questionário semiestruturado (Cavalcante, } \\
\text { Vasconcelos, \& Grosseman, 2017a) sobre as respostas dos internos à } \\
\text { pergunta "Como vem sendo ensinada a comunicação de más notícias } \\
\text { no curso médico?". }\end{array}$ \\
\hline \multicolumn{3}{|l|}{ 2. Terapêutica } \\
\hline Planejamento & $\begin{array}{l}\text { Internos, } \\
\text { pesquisadora e } \\
\text { docente. }\end{array}$ & $\begin{array}{l}\text { Convite à participação + disponibilização e uso do aplicativo móvel } \\
\text { "Comunicando Más Notícias". }\end{array}$ \\
\hline Intervenção & $\begin{array}{l}\text { Internos e } \\
\text { pesquisadora. }\end{array}$ & $\begin{array}{l}\text { Aprendizagem com base em simulação: workshop (aplicativo móvel e } \\
\text { role-play) + diário do pesquisador. }\end{array}$ \\
\hline Avaliação & $\begin{array}{l}\text { Internos e } \\
\text { pesquisadora. }\end{array}$ & $\begin{array}{l}\text { Formulários com registro da avaliação das habilidades observadas } \\
\text { interpares: habilidade presente }(\mathrm{S}) \text {, parcial }(\mathrm{P}) \text { ou ausente }(\mathrm{N})+ \\
\text { relatos dos internos registrados no diário do pesquisador }+ \text { feedback } \\
\text { da oficina por meio de correio eletrônico, registrado no diário do } \\
\text { pesquisador. }\end{array}$ \\
\hline
\end{tabular}

\subsection{Procedimentos Metodológicos}

A intervenção foi planejada por meio de uma estratégia de ensino-aprendizagem com a técnica simulada do role-play, agregada ao uso do aplicativo móvel. O mobile learning surge como uma importante alternativa e, conforme Marçal, Andrade e Rios (2005), destaca-se o seu objetivo de fornecer meios para o desenvolvimento de métodos inovadores de ensino e de treinamento. Para minimizar um possível distanciamento dos cenários de prática, o $\mathrm{m}$ learning pode ser usado agregado a uma técnica de simulação, como é proposto neste estudo.

Foram organizados workshops para discussão e treinamento da CMN, em 5 encontros, para grupos de 6 a 11 internos, reunidos durante o estágio de cirurgia geral. O processo consistia, inicialmente, em um resgate de casos reais vivenciados pelos internos e na revisão dos passos elencados no aplicativo para CMN. Em seguida, os internos eram convidados a uma atividade simulada de role-play, distribuídos em duplas: um interpretava o médico que comunicaria a má notícia; o outro, o paciente ao qual se dirigiria a comunicação. Em todos os workshops, foram usados os mesmos casos fictícios (um de diagnóstico de HIV e outro de 
melanoma na face com possível deformidade pela cirurgia). O script do papel do médico e do paciente era fornecido no momento da atividade.

O interno que comunicava o caso fictício tinha suas habilidades computadas pelo outro interno em um formulário de avaliação. Em seguida, invertiam-se os papéis. Quando o número do grupo era ímpar, formava-se um trio, em que um dos participantes interpretava um familiar. $O$ participante que interpretava o médico tinha a missão de comunicar a má notícia usando os cinco passos discutidos na oficina, a partir do aplicativo móvel. Os participantes que interpretavam o paciente e o familiar tinham a missão de reagir de um modo próximo ao que ocorreria com um paciente real. As impressões do pesquisador durante a realização da simulação foram registradas em um diário, que continha, também, os relatos que os internos construíram durante a fase de intervenção e avaliação.

\subsection{A Técnica do Role-play}

O role-play, estratégia de simulação para o ensino das habilidades de comunicação, é uma técnica na qual os internos são convidados a atuar, em um contexto, interpretando papéis específicos (Rabelo \& Garcia, 2015). No caso da CMN, solicita-se que atuem de acordo com o esperado em uma situação real, no papel do especialista, do paciente ou do familiar. O uso do role-play, para Rabelo e Garcia (2015), proporciona a vivência de várias formas de aprendizado. Dessa maneira, o interno que faz o papel do "médico" pode exercitar a interação com o paciente, o domínio do conteúdo e os passos da transmissão da comunicação por meio de uma conduta humanizada. O interno que faz o papel do "paciente" ou do "familiar" pode exercitar o desenvolvimento da empatia. E, no papel de observador, pode exercitar a reflexão e a interação com os colegas ao emitir sua avaliação sobre a condução da cena.

\subsection{Uso do Aplicativo para Dispositivos Móveis}

Outra estratégia mobilizada foi o aplicativo móvel "Comunicando Más Notícias" (Cavalcante, Vasconcelos, \& Grosseman, 2017b) (figura 2). Desenvolvido para Android e iOS pelo pesquisador e por dois professores, com assessoria de um analista, apresenta cinco passos já estabelecidos, na literatura, para orientar a comunicação de más notícias. O primeiro referese à preparação do profissional e do espaço para a reunião com o paciente/familiar. 0 segundo passo envolve verificar até que ponto o paciente e/ou o familiar já entende a situação. O terceiro passo é comunicar a informação com sensibilidade e linguagem acessível: emitir sinal de alerta, usar frases que indiquem que más notícias virão, evitar o uso de palavras 
excessivamente técnicas e verificar a compreensão. O quarto passo envolve responder, com empatia, às emoções demonstradas pelo paciente. O quinto passo envolve a criação de planos de acompanhamento concretos, tanto no âmbito médico quanto no pessoal.

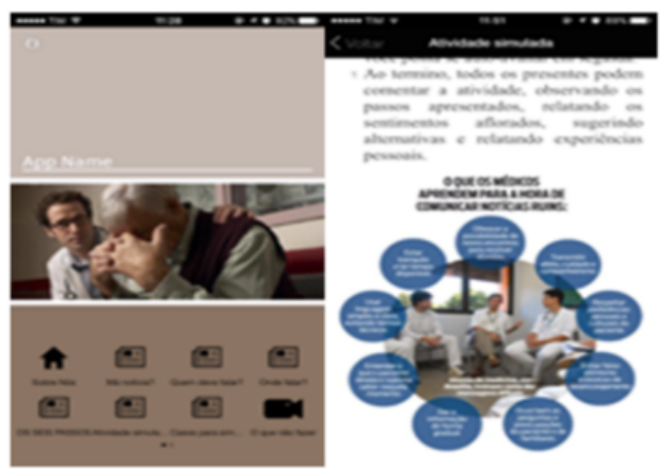

Figura 2. Aplicativo móvel Comunicando Más Notícias.

O formulário (checklist) utilizado para avaliação das habilidades continha os mesmos passos apontados no aplicativo. Ao final do workshop, procedeu-se à avaliação: o participante que interpretou o paciente assinalava, no checklist, (S) para habilidade presente, (P) para habilidade parcial e $(\mathrm{N})$ para habilidade ausente, conforme o que o interno, interpretando o "médico", apresentava. Em seguida, os papéis se invertiam.

\subsection{Análise dos dados}

Os dados do checklist foram tabulados em planilhas Microsoft Excel para Windows ${ }^{\circledR}$ e tratados através da estatística descritiva, com uso da distribuição de frequências. Já as anotações do diário do pesquisador, contendo as observações da etapa de simulação e os relatos dos internos na fase de avaliação, foram submetidas à técnica de análise de conteúdo, com base em Malheiros (2011).

Os temas que convergiam para uma base de conteúdos comuns foram agrupados nas seguintes categorias de análise: I - A comunicação de más notícias e o fazer médico e II - O treinamento em comunicação de más notícias (Quadro 1). 
Quadro 1. Categorias de análise dos temas (2019).

\begin{tabular}{|c|c|}
\hline $\begin{array}{c}\text { Categoria I - A comunicação de más } \\
\text { notícias e o fazer médico }\end{array}$ & $\begin{array}{l}\text { Categoria II - O treinamento em } \\
\text { comunicação de más notícias }\end{array}$ \\
\hline $\begin{array}{l}\text { - Experiências prévias em comunicação de } \\
\text { más notícias }\end{array}$ & $\begin{array}{l}\text { - Treinamento em comunicação de más } \\
\text { notícias }\end{array}$ \\
\hline $\begin{array}{l}\text { - A dificuldade na comunicação de más } \\
\text { notícias }\end{array}$ & - O lidar com as emoções dos pacientes \\
\hline - Falhas na formação médica & $\begin{array}{l}\text { - O fortalecimento da relação médico- } \\
\text { paciente }\end{array}$ \\
\hline
\end{tabular}

As informações sistematizadas trazem os resultados das abordagens quantitativa e qualitativa, uma vez que se complementam. Os dados referentes aos passos elencados no checklist integraram a categoria "O treinamento em comunicação de más notícias".

\section{RESULTADOS E DISCUSSÃO}

Participaram da pesquisa todos os 36 estudantes do internato: $19(52 \%)$ do sexo masculino e 17 (48\%) do sexo feminino, com idades entre 22 e 30 anos. Participaram, voluntariamente, de todas as etapas do processo.

Sob a orientação da pesquisadora e do docente, a atividade iniciava com uma disposição circular dos participantes. Todos se viam e eram convidados a interagir. As apresentações começavam pela moderadora, com nome e função na instituição. Essa dinâmica permitiu aos participantes, principalmente, trabalharem em equipe, favorecendo a aprendizagem. Todos os participantes exploraram as funcionalidades do aplicativo móvel na semana que antecedeu o workshop. Os passos para a CMN foram revisados e exemplificados no momento da atividade. Softwares com objetivos educacionais são comuns já há algumas décadas. A inovação, neste estudo, reside na abordagem de um tema complexo, que envolve variados aspectos da relação médico-paciente, desde o processo de adoecimento até as relações sociais nele implicadas.

\subsection{Categoria I - A Comunicação de Más Notícias e o Fazer Médico}

Os internos foram solicitados a compartilhar experiências em CMN que observaram ou de que participaram anteriormente. Um aluno relembrou a experiência vivenciada quando o avô faleceu e a forma como o profissional de saúde deu a notícia a sua família: 
[...] Quando meu avô faleceu, eu ainda estava no primeiro ano do curso e a notícia foi dada na porta de uma UTI, pelo médico de máscara e em pé. Meu pai ficou devastado e me disse: "Meu filho, você vai ser médico, mas nunca seja como esse médico que nos deu essa notícia hoje" (Interno 1)

Observa-se que a comunicação de uma má notícia, seja referente a um paciente idoso ou pediátrico, se realizada de forma insensível, quase rude, pode trazer perturbações e deixar marcas duradouras na família (Contro, Larson, Scofield, Sourkes, \& Cohen, 2002).

Os internos informaram que se sentiam mal ao comunicar uma má notícia a um paciente ou familiar. A dificuldade de expressar sentimentos é evidente, ainda, por parte deles e mesmo dos médicos. Há certo confundimento entre envolvimento/empatia e falta de limite profissional, pois os sentimentos são vistos como falhas.

O sentimento é recorrente nos relatos que demonstram o quanto isso os impacta:

[...] No estágio de nefrologia, o pior momento era informar a necessidade definitiva de hemodiálise. Os pacientes antigos reagiam melhor que os que recém-chegados ao programa; a reação era como se a vida tivesse acabado e a função do comunicador era mostrar que ainda assim havia possibilidade de uma vida ativa (Interno 5).

Segundo Cruz e Riera (2016), a comunicação deve não apenas incluir o que o paciente precisa saber, mas ser realizada de forma apropriada, assegurando que ele compreenda a informação, preocupando-se com sua reação afetiva e com a retenção da informação. A ausência de orientação, preparação ou formação convencional para comunicar más notícias ficou evidente nos relatos.

Assim, passaram pela vivência de comunicar uma má notícia antes de ter qualquer treinamento sobre o tema e demonstraram surpresa ao perceberem que uma habilidade tão necessária nunca fora abordada, de forma efetiva, em sua formação.

Essa informação corrobora os resultados do estudo sobre o ensino de CMN aos internos, de Cavalcante, Vasconcelos e Grosseman (2017a), que demonstrou que o ensino dessa habilidade não aparece no currículo. Habitualmente, os médicos aprendem, de uma maneira informal e não sistematizada, a comunicar más notícias na pratica diária, geralmente observando outros médicos, o que nem sempre resulta em uma boa prática (Lino, Augusto, Oliveira, Feitosa, \& Caprara, 2011). Uma interno relata, ainda: 
[...] Quando acompanhei um caso avançado de câncer de vias biliares na enfermaria da clínica cirúrgica e sabia do mau prognóstico, todos os dias a filha da paciente perguntava se a mãe ficaria curada e eu não sabia o que responder. Fiquei incomodada porque os dias se passavam e o cirurgião responsável pelo caso ainda não havia conversado com a família (Interno 25).

Mesmo que a atuação profissional traga mais desenvoltura para comunicar más notícias, muitos médicos não se sentem seguros para a tarefa.

Para realizar a comunicação de uma má notícia, é fundamental que o próprio médico se prepare, tendo em mente o que sabe da doença e as possibilidades de tratamento a oferecer ao paciente.

Precisa falar de forma franca, com compaixão e respeito, mantendo-se à disposição para retirar dúvidas (Cruz \& Riera, 2016).

Os participantes relataram que, no caso de pacientes internados, é comum que perguntas sobre sua evolução sejam feitas à enfermagem ou a outras pessoas do hospital, como se a equipe médica "escondesse" as informações. Segundo Meert et al. (2008), as informações contraditórias fornecidas por membros da equipe podem dificultar a confiança no tratamento e a compreensão, pelo doente, do seu real estado.

Nesse sentido, a CMN deveria envolver um diálogo mais efetivo entre os profissionais da equipe, para que a mesma linguagem fosse adotada com os pacientes, o que traria maiores benefícios para eles.

\subsection{Categoria II - $O$ treinamento em Comunicação de Más Notícias}

$\mathrm{Na}$ atividade com o role-play, os alunos apresentaram-se motivados e dispostos.

O aluno que interpretava o paciente tentava, a todo custo, dificultar a comunicação do colega com perguntas e emoções muito próximas do real.

De acordo com Rolim (2004), a abordagem metodológica da pesquisa-ação permite associar ao processo de investigação a possibilidade de aprendizagem pelo envolvimento criativo e consciente dos participantes. 
Tabela 2. Habilidades de comunicação observadas nos internos de medicina/Ufal, em relação ao processo de comunicação de más notícias (2019).

\begin{tabular}{|c|c|c|c|}
\hline PASSOS PARA COMUNICAR MÁ NOTÍCIA & $\begin{array}{l}\text { PRESENTE } \\
\text { (S) }\end{array}$ & PARCIAL(P) & AUSENTE(N) \\
\hline \multicolumn{4}{|l|}{ I - Preparação } \\
\hline (1) Checa informações sobre o caso previamente. & 83,00 & 11,00 & 6,00 \\
\hline (2) Cumprimenta e se apresenta ao paciente. & 75,00 & 22,20 & 2,70 \\
\hline (3) Contato visual / postura adequada. & 88,80 & 8,30 & 2,70 \\
\hline \multicolumn{4}{|l|}{ II - Percepção } \\
\hline (1) Avalia o que o paciente sabe. & 77,70 & 19,40 & 2,70 \\
\hline \multicolumn{4}{|l|}{ III - Compartilhamento de informações } \\
\hline (1) Fornece um "aviso" antes de passar a notícia. & 72,20 & 22,20 & 5,50 \\
\hline (2) Passa as informações de forma clara e pausada. & 77,70 & 22,20 & 0,0 \\
\hline $\begin{array}{l}\text { (3) Avalia o que o paciente quer saber antes de } \\
\text { passar mais informações. }\end{array}$ & 75,00 & 13,00 & 11,10 \\
\hline \multicolumn{4}{|l|}{ IV - Resposta às emoções } \\
\hline (1) Reconhece a emoção. & 69,00 & 25,00 & 5,50 \\
\hline (2) Legitima a emoção. & 55,50 & 30,50 & 13,80 \\
\hline (3) Explora as principais preocupações do paciente. & 69,00 & 25,00 & 6,00 \\
\hline \multicolumn{4}{|l|}{ V - Plano e seguimento } \\
\hline (1) Compartilha perspectivas terapêuticas. & 100,00 & 0,00 & 0,00 \\
\hline (2) Estabelece parceria. & 80,00 & 13,80 & 6,20 \\
\hline $\begin{array}{l}\text { (3) Verifica condições do paciente para a saída da } \\
\text { consulta. }\end{array}$ & 33,30 & 13,80 & 52,70 \\
\hline
\end{tabular}

$\mathrm{Na}$ atividade de simulação, nos passos de I a III do checklist, a resposta às habilidades mostrou-se satisfatória (adequação de habilidade $\geq 70 \%$ ), variando entre $72,2 \%$ e $88,8 \%$. Os alunos mostraram-se preparados para o contato inicial com o paciente, avaliando o que ele já conhecia sobre sua doença para, então, compartilhar a má notícia.

No passo IV, o desempenho variou de $55,5 \%$ a $69 \%$, abaixo do índice considerado para adequação da habilidade ( $\geq 70 \%$ ), o que demonstra a dificuldade para lidar com as emoções 
do paciente: "[...] Tive dificuldade de dizer a palavra que consola na hora certa" (Interno 17). $\mathrm{O}$ resultado com scores mais baixos remete à empatia médica. A empatia corresponde à habilidade de imaginar os sentimentos dos outros (emocional), à motivação para ser empático (moral), à capacidade de identificar/entender as reações (cognitivo) e à forma de mostrar esse entendimento (comportamental). Assim, a empatia passa a ser uma questão relevante na prática médica (Provenzano, Machado, Rangel, \& Aranha, 2014). No inquérito aplicado por Baile et al. (2000), 64,2\% dos médicos responderam que se sentiam pouco confortáveis no trato com as emoções do paciente. Esse aspecto parece causar insegurança ao médico ou aos internos em diferentes épocas e regiões do mundo.

Na etapa final, cujo objetivo é a criação de planos de seguimento, a habilidade obteve índices de $100 \%$ e $80 \%$, demonstrando a capacidade do aluno de propor estratégias de tratamento. No entanto, no item em que o médico deveria avaliar as condições em que o paciente se encontrava na saída da consulta, o índice foi de apenas 33,3\%, demonstrando a dificuldade para lidar com o impacto que a má notícia gerou em seu paciente e confortá-lo.

Para Girgis e Sanson-Fisher (1995), citando o Código de Ética Americano, "a vida de uma pessoa doente pode ser abreviada não somente pelos atos, mas também pelas palavras ou conduta do médico. É, portanto um dever sagrado proteger o paciente evitando tudo o que puder desencorajá-lo e deprimir o seu espírito".

O treinamento para CMN era visto, pelos internos, como algo que beneficiava apenas o paciente e a família. No entanto, ficaram surpresos quando perceberam que estavam tão envolvidos nessa dinâmica quanto quem recebe a má notícia, e que também são afetados pelas emoções e repercussões que ela gera na vida do paciente (diário do pesquisador). Analisando as médias da aquisição de habilidades nas etapas de treinamento no workshop (média das etapas: I - 82,3\%, II - 77,7\%, III - 75\%, IV - 64,5\%, V - 71,1\%), as do item I (preparação) foram as que, em conjunto, obtiveram o maior registro de adequação pelos participantes $(82,3 \%)$, enquanto as do item IV (resposta às emoções) tiveram o menor registro $(64,5 \%)$, demonstrando a necessidade de estratégias que visem a preparar o aluno para encarar as emoções e o impacto que uma notícia negativa desencadeia nos pacientes.

[...] Eu participei dos momentos de paliação do meu pai, e a minha família havia decidido não informá-lo sobre a doença, pensando ser o melhor para ele, sem nunca ter perguntado seus desejos, mas depois da oficina eu me questionava se havia sido a melhor postura (Interno 2). 
Após as oficinas, os alunos relataram que suas maiores dificuldades foram responder perguntas específicas do tratamento e lidar com as emoções dos pacientes. Algo que os surpreendeu, no treinamento, foi o fato de que a boa comunicação em saúde afeta não só o paciente, mas também quem comunica, e que a qualidade do diálogo e da comunicação é fundamental não apenas para a boa execução do trabalho médico, mas também para manter a saúde de toda a equipe que atende esse paciente (diário do pesquisador). Os alunos enviaram, voluntariamente, um feedback relatando experiências de comunicação de más notícias que tiveram após o treinamento, bem como o efeito positivo deste em seus desempenhos nos outros estágios (diário do pesquisador). Cerca de três semanas após uma das oficinas.

[...] uma participante pediu para me acompanhar no ambulatório de cirurgia de cabeça e pescoço. Queria ver casos reais na prática. Coincidentemente, naquele dia, atendemos um jovem de 30 anos com uma neoplasia de ossos da face. A cirurgia seria mutiladora, mas a única forma de salvar a vida dele. Usei todo o protocolo! Quando o paciente saiu, a aluna me perguntou: "Como a senhora consegue? Eu me envolvo demais". Preciso ser mais fria!". Expliquei que eu estava destroçada, mas isso não ajudava ao paciente e nem a mim, e nós ainda tínhamos uma dezena de outras pessoas que precisavam igualmente da nossa melhor atenção! Então o propósito era fazer o nosso melhor! Usar a técnica com a melhor empatia possível, que é diferente de pena ou culpa! E fazer o paciente entender que o tratamento seria um compartilhamento de responsabilidades. A aluna, que antes tinha cara de choro, ficou muito mais leve a partir de então. Terminamos os atendimentos naquele dia com sorrisos - vimos casos felizes também - e ela não cansava de expressar o quão estava grata pela oportunidade de ter vivido aquela experiência (diário do pesquisador).

O relato da interna frente a um caso real demonstra a dificuldade de unir, na prática, a comunicação e a empatia. Batista e Lessa (2019) relatam que a atuação médica é uma atividade gratificante, mas é, também, estressante, pelo frequente contato com a dor e o sofrimento dos pacientes. Por outro lado, o modelo biopsicossocial possibilita a interação mais precoce, melhorando a compaixão, a empatia e a comunicação, contribuindo para a maturidade intelectual (Kaluf, Sousa, Luz, \& Cesario, 2019). As avaliações do workshop mostram aos gestores do curso, aos docentes responsáveis pelo internato e aos internos a importância de incluir, formalmente, o tema "comunicação de más notícias" no currículo do curso de medicina, para que o aluno possa ter a oportunidade de melhorar a relação médicopaciente, bem como sinalizar os pontos que necessitam de maior atenção ou de aplicação de estratégias para auxiliá-lo no trabalho que irá desempenhar. 


\section{CONCLUSÃO}

Este artigo, fundamentado na pesquisa-ação educacional, pretendeu analisar a percepção do interno em Medicina sobre a aplicação de uma estratégia para o ensino da comunicação de más notícias, utilizando uma técnica de simulação de atendimento, como o role-play, integrada ao uso de um aplicativo móvel. A utilização dessa técnica resultou na preparação do interno frente a uma situação simulada, conferindo-Ihe experiência na transição para o atendimento em uma situação real. A técnica possibilitou, ainda, que os internos se colocassem em diferentes situações: como médico, paciente e acompanhante. Isso lhes permitiu trabalhar as próprias emoções nas diversas circunstâncias. Além do conteúdo técnico e científico, a comunicação de más notícias envolve o desenvolvimento de outras habilidades. A pesquisa demonstrou resultados favoráveis no processo de desenvolvimento de habilidades comunicativas e relacionais. O retorno dos alunos sobre o efeito positivo da técnica na maneira como passaram a se relacionar com os pacientes, notadamente ao comunicar uma notícia negativa, mostra a eficácia da pesquisa-ação intervencionista no curso médico. A técnica integrada trabalha o tema através de métodos e momentos diferentes, facilitando a fixação do conteúdo. Outros estudos são necessários para avaliar a eficácia do aprendizado a longo prazo, com o uso do aplicativo agregado à técnica de simulação, bem como seus benefícios na prática médica em situações reais.

\section{REFERÊNCIAS}

Baile, W. F., Buckman, R., Lenzi, R., Glober, G., Beale, E. A., \& Kudelka, A. P. (2000). SPIKES - A six-step protocol for delivering bad news: application to the patient with cancer. Oncologist, 5(4), 302-311.

Batista, N. A., \& Lessa, S. S. (2019). Aprendizagem da empatia na relação médico-paciente: um olhar qualitativo entre internos do internato de escolas médicas do nordeste do Brasil. Rev Bras Educ Med, 43(1), 349-356.

Brasil. (2014). Resolução CNE/CES $n^{\circ}$ 3, de 20 de junho de 2014. Institui Diretrizes Curriculares Nacionais do curso de graduação em Medicina e dá outras providências. Brasília: Ministério da Educação.

Cavalcante, M., Vasconcelos, M., \& Grosseman, S. (2017a). A Comunicação de Más Notícias por Internos de Medicina: Um Estudo de Caso. Atas - Investigação Qualitativa em Saúde, Portugal, 1642-1653.

Cavalcante, M., Vasconcelos, M. V. L., \& Grosseman, S. (2017b). Comunicando más notícias [aplicativo móvel]. Disponível em: <https://comunicando-mas-noticias.seuapp.com>. Access in: 27 jan. 2019.

Contro, N., Larson, J., Scofield, Sourkes, B., \& Cohen, H. (2002). Family perspectives on the quality of pediatric paliative care. Arch Pediatr Adolesc Med, 156, 14-19.

Creswell, J. W. (2010). Projeto de pesquisa: métodos qualitativo, quantitativo e misto. (3a ed). Porto Alegre: Artmed.

Cruz, C. O, \& Riera, R. (2016). Comunicando más notícias: o protocolo SPIKES. Diagn Tratamento, 21(3), 106108. 
Girgis, R. W., \& Sanson-Fisher, A. (1995). Breaking Bad News: Consensus Guidelines for Medical Practitioners. J Clin Oncol, 13(9), 2449-2456.

Kaluf, I. O., Sousa, S. G. O., Luz, S., Cesario, R. R. (2019). Sentimentos do interno de Medicina quando em contato com a prática. Rev Bras Educ Med, 43(1), 13-22.

Kolb, A. Y., \& Kolb, D. A. (2005). Learning styles and learning spaces: enhancing experiential learning in higher education academy of management. Learning \& Education, 4(2), 193-212.

Leal-Seabra, F., \& Costa, M. J. (2015). Comunicação de más notícias pelos médicos no primeiro ano de internato: um estudo exploratório. Rev. la Fund. Educ. Médica, 18(6), 387-395.

Lino, C. A., Augusto, K. L., Oliveira, R. A. S., Feitosa, L. B., \& Caprara, A. (2011). Uso de protocolos spikes no ensino de habilidades de transmissão de más notícias. Rev Bras Educ Med, 35, 52-55.

Malheiros, B. T. (2011). Metodologia da pesquisa em educação. Rio de Janeiro: LTC.

Marçal, E., Andrade, R., \& Rios, R. (2005). Aprendizagem utilizando dispositivos móveis com sistemas de realidade virtual. Revista Novas Tecnologias na Educação, 3(1), 1-11.

Meert, K. L., Eggly, S., Pollack, M., Anand, K. J. S., Zimmerman, J., \& Carcillo, J. (2008). Parent's perspective on physicians-parent communication near the tima of a child's death in the pediatric intensive care unit. Pediat Criti Care Med, 9, 5-7.

Nonino, A., Magalhães, S. G., \& Falcão, D. P. (2012). Treinamento médico para comunicação de más notícias: revisão da literatura. Revista Brasileira de Educação Médica, 36(2), 228-233.

Penteado, H. D., \& Garrido, E. (2010). Pesquisa-ensino: uma modalidade de pesquisa-ação. In Penteado, H. D., \& Garrido, E. Pesquisa-ensino: a comunicação escolar na formação do professor. São Paulo: Paulinas.

Provenzano, B. C., Machado, A. P. G., Rangel, M. T. A. S., \& Aranha, R. N. (2014). A empatia médica e a graduação em medicina. Revista HUPE, 13(4).

Rabelo, L., \& Garcia, V. L. (2015). Role-Play para o desenvolvimento de habilidades de comunicação e relacionais. Revista Brasileira de Educação Médica, 39(4), 586-596.

Rolim, L. R. (2004). O professor de educação física na educação infantil: uma revisão bibliográfica (Dissertação de mestrado, Centro Universitário 9 de Julho - UNINOVE).

Rosenbaum, M. E., Ferguson, K. J., \& Lobas, J. G. (2004). Teaching medical students and residents skills for delivering bad news: a review of strategies. Acad Med., 79(2), 107-117.

Stiefel, F., Barth, J., Bensing, J., Fallowfield, L., Jost, L., Razavi, D., \& Kiss, A. (2010). Communication skills training in oncology: a position paper based on a consensus meeting among European experts in 2009. Annals of Oncology, 21(2), 204-207.

Thiollent, M. (2011). Metodologia da pesquisa-ação. São Paulo: Cortez.

Traiber, C., \& Lago, P. M. (2012). Comunicação de más notícias em pediatria. Boletim Científico de Pediatria, 1(1).

Tripp, D. (2005). Pesquisa-ação: uma introdução metodológica. Educação e pesquisa, 31(3), 443-466.

Turini, B., Martins-Neto, D., Tavares, M. S., Nunes, S. O. V., Silva, V. L. M., \& Thomson, Z. (2008). Comunicação no ensino médico: experiência, estruturação e desafios em novos currículos médicos. Revista Brasileira de Educação Médica, 32(2), 264-270.

Victorino, A. B., Nisenbaum, E. B., Gibello, J., Bastos, M. Z. N., \& Andreoli, P. B. A. (2007). Como comunicar más notícias: revisão bibliográfica. Rev. da $S B P H, 10,53-63$. 